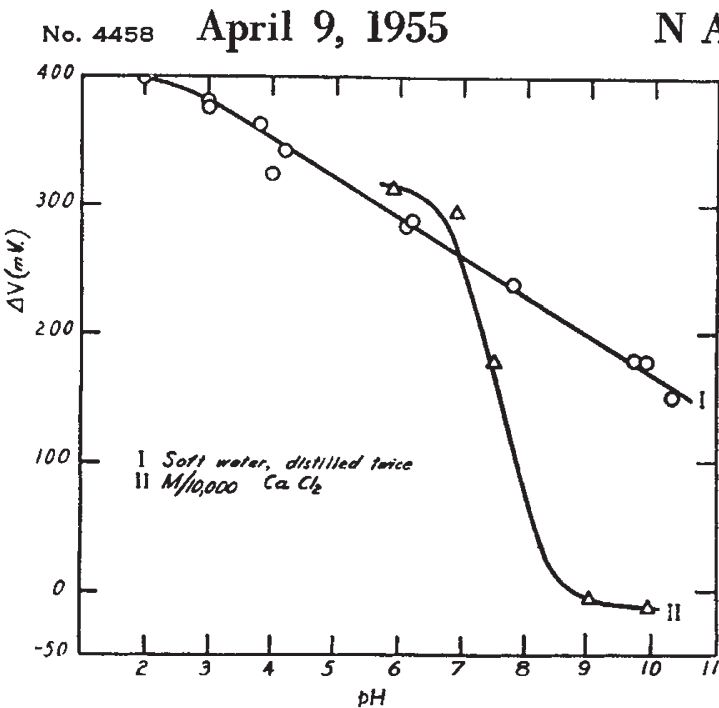

Fig. 2. Dependence of surface potential on $p$ H for compressed monolayers of stearic acid on pure water and on a dilute solution of calcium chloride

The increase in purity produced by successive distillations of the hard water is seen from the way in which curves III and IV approach curve I. However, even after the third distillation, sufficient calcium is still present to cause a slight depression in $\sigma_{0}$ at high $p \mathrm{H}$ values.

Surface potential measurements, made with a radioactive electrode under the same conditions as the $(\pi-A)$ curves, gave the results presented in Fig. 2. The values of $\Delta V$ are the potentials, no longer dependent upon pressure, obtained when the film is compressed to an area/molecule less than $\sigma_{0}$. The films behaved reversibly, and the measurements were reproducible to within about $10 \mathrm{mV}$. With the purest water, $\Delta V$ decreases apparently linearly from $+400 \mathrm{mV}$. at $p \mathrm{H} 2$ to $+170 \mathrm{mV}$. at $p \mathrm{H} 10$. With a very dilute solution of calcium chloride, $\Delta V$ drops suddenly at $p \mathrm{H} 7$ to a slightly negative value at $p \mathrm{H} 9$ (curve II, Fig. 2). This curve is strikingly similar to previously published $(\Delta V-p \mathrm{H})$ curves $^{4}$ in which the sudden drop in $\Delta V$ has been ascribed to ionization. This similarity suggests that unsuspected impurities reacting with the acid to form a soap are also responsible for the more negative potentials observed by other workers at high $p \mathrm{H}$ values. These workers, however, used buffered solu. tions of much greater ionic strength than those used in our own experiments.

The results show that of itself ionization in the monolayer has no appreciable effect on the $(\pi-A)$ characteristics of stearic acid, and a much smaller effect on the surface potential than previously supposed. It is also demonstrated that if a hard water is to be purified by distillation, the process must be carried out carefully and repeatedly before the effects of dissolved impurities on the properties of acid monolayers can be eliminated.

Division of Tribophysics,

Commonwealth Scientific and

Industrial Research Organization,

University of Melbourne. Dec. 20.

${ }^{1}$ Lyons, C. G., and Rideal, E. K., Proc. Roy. Soc., A, 124, 323 (1929). 2 Marsden, J., and Schulman, J. H., Trans. Farad. Soc., 34, 748 (1938). ${ }^{3}$ Sasaki, T., and Matuura, R., Bull. Chem. Soc. Japan, 24, 274 (1951). ${ }^{4}$ Schulman, J. H., and Hughes, A. H., Proc. Roy. Soc., A, 138, 436 (1932). Glazer, J., and Dogan, M. Z., Trans. Farad. Soc., 49, 448 (1953).

s Anderson, V. G., J. and Proc. Aust. Chem. Inst., 7, 187 (1940).

$$
\text { J. V. SANDERS }
$$$$
\text { J. A. SPINK }
$$

\section{Proton Magnetic Resonance Spectra of Coals}

Proton magnetic resonance spectra can give information about the arrangement of the hydrogen atoms in a solid ${ }^{1}$. Preliminary measurements have been made which suggest that this method may provide useful information about the distribution of hydrogen atoms in coal.

Samples were prepared from hand-selected lumps of bright coals containing more than 50 per cent vitrain. The samples were ground into cylinders of $6.25 \mathrm{~mm}$. diameter $\times 3 \mathrm{~cm}$. long, the axis of the cylinder lying in the bedding plane. Part of the inherent moisture content of the samples was removed by heating them to $80^{\circ} \mathrm{C}$. under a pressure of $0.2 \mathrm{~mm}$. of mercury for $4 \mathrm{hr}$. The samples were then sealed into glass tubes to prevent resorption of moisture. Nuclear resonance measurements were made at $90^{\circ} \mathrm{K}$. using the apparatus described by Richards and Smith ${ }^{2}$ and by Pratt and Richards ${ }^{3}$.

The second moments of the proton resonance absorption lines were obtained for three samples and are given in Table 1, together with the constitution of the coals. A slight anisotropy of line shape with orientation of the sample in the magnetic field was observed with the Llandebie, but not with the other coals.

\begin{tabular}{|c|c|c|c|c|c|c|}
\hline Coal & $\begin{array}{l}\text { N.C.B. } \\
\text { Code } \\
\text { No. }\end{array}$ & $\begin{array}{l}\text { Perc } \\
\text { Moisture }\end{array}$ & $\begin{array}{l}\text { ntage co } \\
\text { Carbon }\end{array}$ & $\begin{array}{l}\text { Astitution } \\
\text { Hydro- } \\
\text { gen }\end{array}$ & Ash & $\begin{array}{l}\text { Second } \\
\text { moment } \\
\text { (gauss) }^{2}\end{array}$ \\
\hline $\begin{array}{l}\text { Llandebie } \\
\text { Monk }\end{array}$ & $100 a$ & 1.5 & $92 \cdot 6$ & $2 \cdot 8$ & $1 \cdot 1$ & 16 \\
\hline $\begin{array}{l}\text { Bretton } \\
\text { Langwith }\end{array}$ & $\begin{array}{l}602 \\
902\end{array}$ & $\begin{array}{l}3 \cdot 2 \\
4 \cdot 8\end{array}$ & $\begin{array}{l}83 \cdot 1 \\
79 \cdot 2\end{array}$ & $\begin{array}{l}5 \cdot 2 \\
5 \cdot 3\end{array}$ & $\begin{array}{l}0 \cdot 4 \\
1.2\end{array}$ & $\begin{array}{l}19 \frac{1}{2} \\
21 \frac{1}{2}\end{array}$ \\
\hline
\end{tabular}

One interpretation of the variation in second moment would be in terms of a variation in the ratio of the number of hydrogen atoms present in saturated hydrocarbon chains or rings to the number of hydro. gen atoms attached to aromatic or graphitic structures. Proton resonance spectra of aromatic hydrocarbons have second moments ${ }^{4}$ of about 10 gauss $^{2}$ and aliphatic hydrocarbons give spectra with second moments ${ }^{5}$ of about 26 gauss $^{2}$. On this interpretation the relative proportion of aliphatic protons increases as the carbon content of the coal decreases. X-ray diffraction investigation $\mathrm{s}^{6}$ on coal samples suggest that the graphitic or aromatic structure increases with increasing rank.

One of us (P. C. N.) wishes to thank the DirectorGeneral of Research, National Coal Board, for permission to publish this communication; the views expressed are not necessarily those of the Board.

$$
\text { P. C. NEWMaN }
$$

Central Research Establishment I, National Coal Board, Stoke Orchard, Glos.

Physical Chemical Laboratories,

L. Pratit

R. E. RICHARDS Oxford.

Feb. 8.

${ }^{1}$ Purcell, E. M., Science, 118, 431 (1953)

${ }^{2}$ Richards, R. E., and Smith, J. A. S., Trans. Farad. Soc., 47, 1261 (1951).

${ }^{3}$ Pratt, L., and Richards, R. E., Trans. Farad. Soc., 49, 744 (1953).

Andrew, E. R., and Eades, R. G., Proc. Roy. Soc., A, 218, 537 (1953).

${ }^{5}$ Andrew, E. R., and Eades, R. G., Proc. Roy. Soc., A, 216, 398 (1953). Andrew, E. R., Physica, 17, 405 (1951).

- Hirsch, P. B., Proc. Roy. Soc., A, 228, 143 (1954). 